\title{
Pelvic floor muscles contraction and sexual function are associated with hormonal treatment in women after breast cancer? $^{*}$
}

\author{
Thais Martins Albanaz da Conceição(1), Thuane Da Roza ${ }^{(2)}$, Keyla Mara dos Santos ${ }^{(3)}$ Soraia Cristina Tonon da Luz ${ }^{(4)}$, \\ Clarissa Medeiros da Luz ${ }^{(5)}$.
}

\begin{abstract}
Introduction: Breast cancer has a high prevalence among women. It is known that breast cancer survivors can undergo a several alterations due to the treatment, including sexual dysfunction. Objective: This study aimed to determine the incidence of sexual dysfunction in women after breast cancer surgery, and assess the relationship between sexual dysfunctions and pelvic floor muscles (PFM) contraction, as well to verify if hormone therapy caused long-term occurrence of PFM weakness or sexual dysfunction. Methods: The sample was composed by 26 women with $48.4 \pm 6.8$ years which using hormone therapy treatment at least six months. Data on sexual dysfunction were collected through the Female Sexual Function Index- FSFI questionnaire and a section composed by demographic information. Furthermore, the PFM contraction was assessed using the PERFECT scale. Results: The results demonstrated a high rate of sexual dysfunction (64.3\%) and a weak PFM contraction (2.31 \pm 1.3$)$ among the women. In addition, a long-term hormone therapy had a negative association with PFM endurance and with the orgasm and satisfaction domains of the FSFI questionnaire. Conclusion: women using hormone therapy after breast cancer surgery had a high rate of sexual dysfunction and the long-term treatment of hormone treatment can be associated with a worsening of orgasm and sexual satisfaction in these women. Also, the use at long-term of hormone therapy had a negative association with the PFM endurance.
\end{abstract}

Keywords: Sexual Dysfunction; Pelvic Floor; Breast cancer; Physiotherapy.

\section{INTRODUCTION}

Breast cancer is an invasive neoplasm with a high incidence rate and mortality among women. About 1.67 million new cases of this neoplasm were expected in 2012, worldwide, representing $25 \%$ of all cancers diagnosed in women. Data from the National Institute of Cancer showed that the estimated risk for developing breast cancer in Brazil has increased in the female population, predicting 57,000 new cases in 2014 and 2015. ${ }^{(1)}$

Notably, in recent years, the number of women surviving breast cancer has also increased, (2) due mainly to the diagnosis at earlier stages and development of more effective therapies. ${ }^{(3)}$ Therefore, the topics of quality of life after breast cancer have become important.

It is known that women with breast cancer experience negative emotions, including depression and anxiety, ${ }^{(4)}$ concerns relapses, ${ }^{(5)}$ and femininity changes. ${ }^{(6)}$ Thus, an important area of quality of life and that has not been properly described in the literature is the sexual health of these women. ${ }^{(7)}$ The female sexual response is complex, involving physical, cultural, hormonal and emotional factors. ${ }^{(8)}$ Studies suggest that almost all women have problems in sexual function after treatment for cancer. ${ }^{(9-11)}$ Among the problems it is important to mention the decrease in sexual desire, ${ }^{(12)}$ the lack of lubrication which may lead to dyspareunia, ${ }^{(13)}$ and difficulty in achieving orgasm. ${ }^{(13)}$ Additionally, hormone therapy may cause vulvovaginal atrophy with subsequent decreased libido and dyspareunia, thus women on hormonal therapy for breast cancer may be at increased risk of increase or develop the symptoms of that disorder. Despite these hypotheses, currently, little is known

\footnotetext{
* This study was developed at the Carmela Dutra Maternity Physiotherapy Clinic in partnership with the State University of Santa Catarina - UDESC, Florianópolis - SC, Brazil.

Mailing address: Thuane Da Roza, Centro de Ciências da Saúde e do Esporte - CEFID. Rua Pascoal Simone, 358 - Coqueiros - Florianópolis - SC, Brazil, CEP: $88080-350$ E-mail: thuaneroza@yahoo.com.br

2 PhD in Physical Activity and Health, Professor at the State University of Santa Catarina - UDESC Florianópolis, Brazil and Collaborator of INEGI, Porto, Portugal. Email: thuaneroza@yahoo.com.br

Full list of author information is available at the end of the article.

Funding: nothing to declare
}

Submission date February 16, 2017; Acceptance April 15, 2017; Publication July 28, 2017 
about the hormonal treatment effects of time in regard of sexual dysfunction.

The pelvic floor muscles (PFM) perform an important role in orgasm (14) and sexual arousal. (15) Studies have shown that the ability and contraction duration of the PFM have been positively associated with sexual function in women with pelvic floor dysfunction. ${ }^{(16)}$ Accordingly, the evaluation of strength and tone ${ }^{(17)}$ of these muscles would enable us to verify several components of the PFM function and hence sexual function. Despite this knowledge, no study has investigated the relationship between PFM function and symptoms of sexual dysfunction particularly in women post cancer undergoing hormone therapy.

Thus, the present study analyzed the correlation of the sexual dysfunctions with the capacity of contraction of the PFM, as well as to verified the effects of the time of hormonal treatment in the contraction capacity of PFM and regarding sexual dysfunction in women after breast cancer which undergo hormone therapy.

\section{METHOD}

It is a cross-sectional study with women undergoing surgical treatment for breast cancer and which were performing hormone therapy for at least six months in Oncology Research Center (CEPON) in Florianópolis, SC, Brazil. Females with pelvic joint restrictions which prevented gynecological assessment, women with urinary tract infection and/or sexually transmitted diseases at the time of physical therapy assessment, who presented cognitive alterations to respond to the questionnaires or to execute the researcher commands, and those who had completed hormone treatment were excluded from the sample.

Participants were recruited in an informative presentation at CEPON about the objectives and benefits of the study. Those who consented to participate were evaluated individually at the Carmela Dutra Maternity Physiotherapy Outpatient Clinic. All participants signed the Free and Informed Consent Term, and the study was conducted in according to the Resolution n. 466/2012 of the National Health Council, after approval in the Committees on Ethics in Research on Human Beings of the institutions involved under CAAE n. 08860713.6.3002.5355.

Data collection occurred in a previously scheduled date, where an identification form was completed containing personal data, history of the disease, associated comorbidities and ongoing hormonal treatment. Symptoms such as dyspareunia, discomfort, dryness and vaginal stenosis, adhesion, and urinary incontinence were also evaluated. Afterwards, the participants answered the questionnaire Female Sexual Function Index - FSFI, validated and translated into Portuguese ${ }^{(18)}$.

The FSFI questionnaire is an instrument used to assess sexual function in women. This questionnaire has 19 specific and multi-dimensional items to report on the six domains of sexual response: sexual desire, arousal, lubrication, orgasm, satisfaction and pain ${ }^{(18)}$. The questions relate to the sexual performance of the woman in four weeks prior to the questionnaire application. The minimum FSFI total score is 2 and the maximum is 36 , with higher scores indicating a better function and lower scores than 26.5 characterize sexual dysfunction.

The evaluation of the PFM contraction capacity was performed by the PERFECT scheme (19) and according to the Functional Assessment of the Pelvic Floor scale (FAP) ${ }^{(20)}$. The evaluation was performed with the patient in dorsal decubitus, flexed knees and abduction hips. The examiner performed the bidigital touch using sterile gloves and lubricating gel during the procedure. Patients were instructed to perform perineal contraction during expiration. Measurement of muscle contraction degree was performed by the same examiner in all participants.

Statistical analysis was performed using the IBM software Statistical Package for the Social Sciences, version 21 (SPSS, Inc, Chicago, Illinois - licensed for use by State University of Santa Catarina). The qualitative variables were analyzed descriptively from frequencies and percentages, while for the quantitative variables mean $\pm S D$, minimum and maximum values were used. The data normality was assessed using the Shapiro-Wilk test. The Spearman correlation test was used to analyze the association among hormone treatment time with the perineal contraction capacity and scores of specific domains of FSFI questionnaire. The Chi-square test verified the association among the qualitative variables. To assess differences in questionnaire FSFI domains between women with and without sexual dysfunction, it was used the independent Mann Whithey $U$ and $p$ values $\leq 0.05$ were considered statistically significant.

\section{RESULTS}

In total, 26 women participated in this study with mean age $48.4 \pm 6.8$ (ranging from 37 to 62 ) years and who underwent hormonal treatment for $25.7 \pm 16.9$ (ranging from 6 to 54) months. No participant reported symptoms of urinary incontinence. Seven women were in menopause before hormone treatment and the other 19 reported hormone-induced menopause. Majority of women were married $(61.5 \%)$, retired $(32.4 \%)$ and had completed high school (61.5\%). Regarding the type of surgery, 12 (46.2\%) had undergone radical mastectomy, while 7 (26.9\%) underwent modified radical mastectomy and another 7 (26.9\%) underwent quadrantectomy.

Regarding sexual issues, 14 (53.9\%) women in the study were sexually active. Of these, 9 (64.3\%) presented a score $<26.5$ of the FSFI questionnaire, with the lowest scores the desire $(p=0.029)$, lubrication $(p=0.004)$ and pain $(p=0.012)$. The Chi-square test showed an association between women 
with sexual dysfunction (score $<26.5$ ) and the adherence symptom ( $p=0.045)$.

Table 1 shows the results of PFM contraction capacity of all women in the study. Regarding the variables of PFM contraction, for the entire group, a negative correlation was found between age and FAP $p=0.042 ; R=-0.042$. Among sexually active women $(n=14)$, the endurance and orgasm

Table 1: Pelvic floor muscle contraction capacity $(n=26)$.

\begin{tabular}{lc}
\hline \multicolumn{1}{c}{ Variable } & Mean \pm SD \\
\hline AFA (muscular strength) & $2.31 \pm 1.3$ \\
PERFECT & \\
Endurance (contraction maintenance) & $2.15 \pm 1.8$ \\
Repetitions (repetitions of maintained contractions) & $4.42 \pm 3.3$ \\
Fast (number of fast contractions) & $5.73 \pm 3.8$ \\
\hline
\end{tabular}

FAP: Functional Assessment of the Pelvic Floor; SD: Standard deviation.
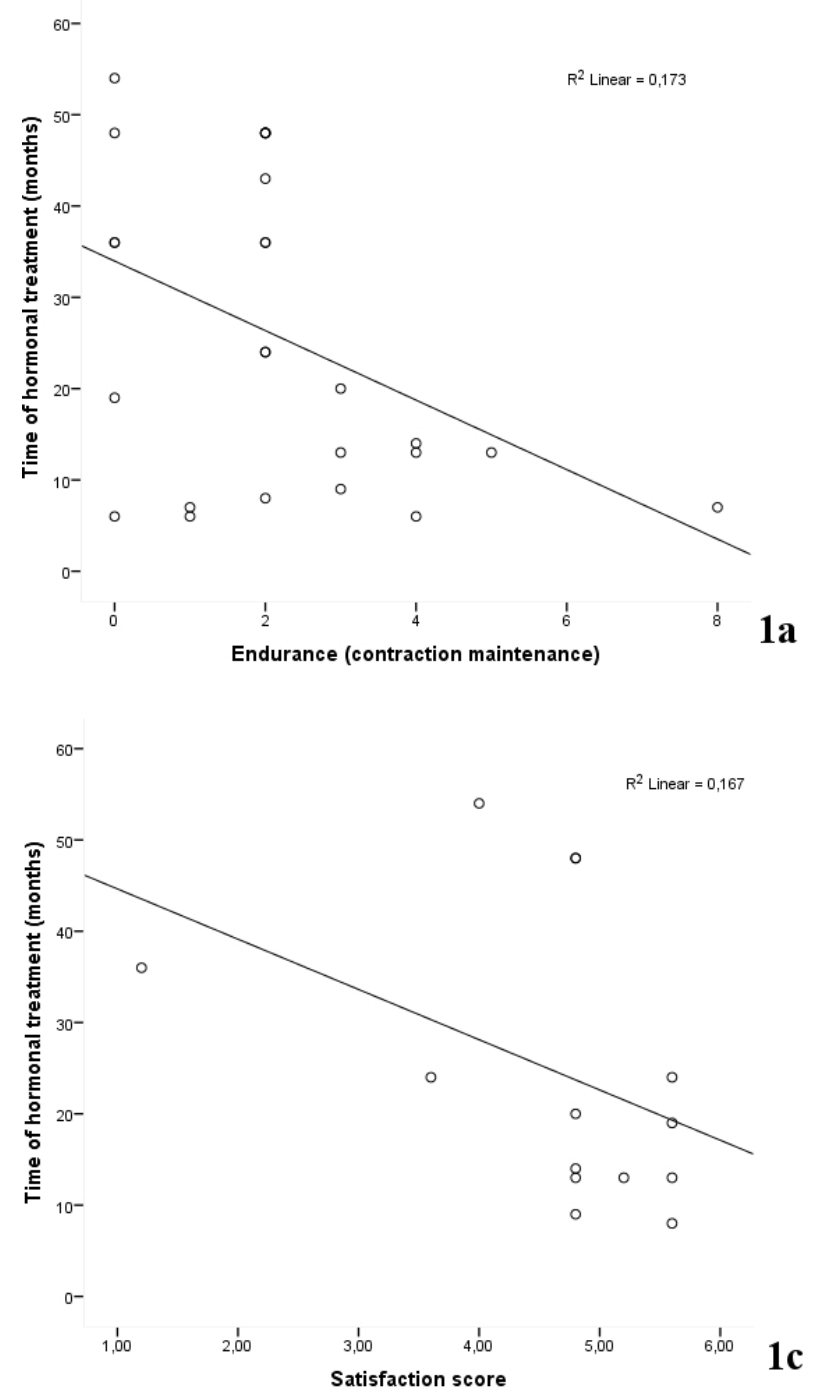

domain in the FSFI questionnaire showed a moderate association ( $p=0.018, r=0.621)$.

Figure 1a shows that hormonal treatment time showed a negative correlation with endurance for the entire group $(n=26)$. In addition, among sexually active women $(n=14)$, that correlation was stronger (Figure 1b). The time of hormonal treatment also showed a negative correlation with the satisfaction and orgasm domains in the FSFI questionnaire (Figure $1 \mathrm{c}$ and $1 \mathrm{~d}$ ) among sexually active women.

\section{DISCUSSION}

In the present study, among 26 participating women, 14 were sexually active and majority (64.3\%) reported sexual dysfunction (score $<26.5$ in the FSFI questionnaire). In addition, the hormonal treatment time was inversely associated with endurance of PFM, as well as the satisfaction and orgasm scores in the FSFI questionnaire.

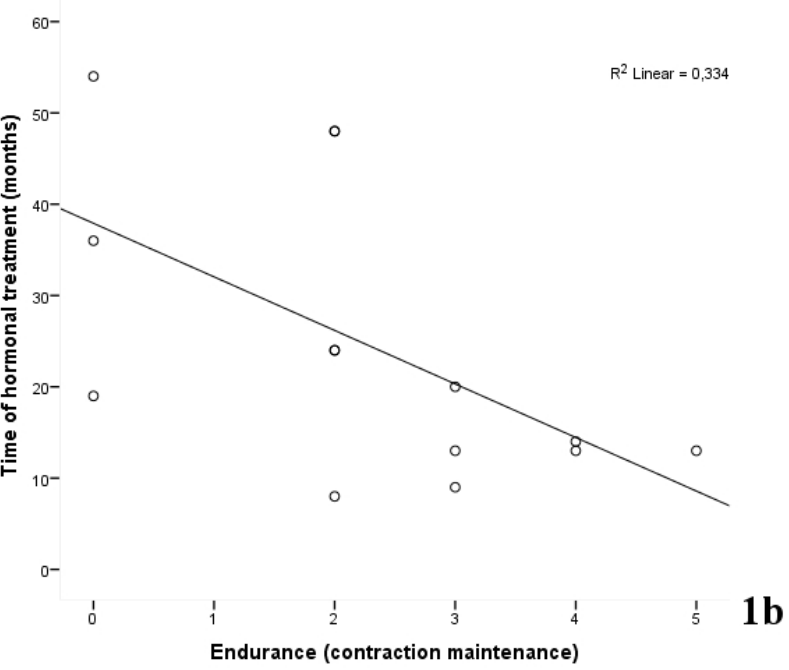

60

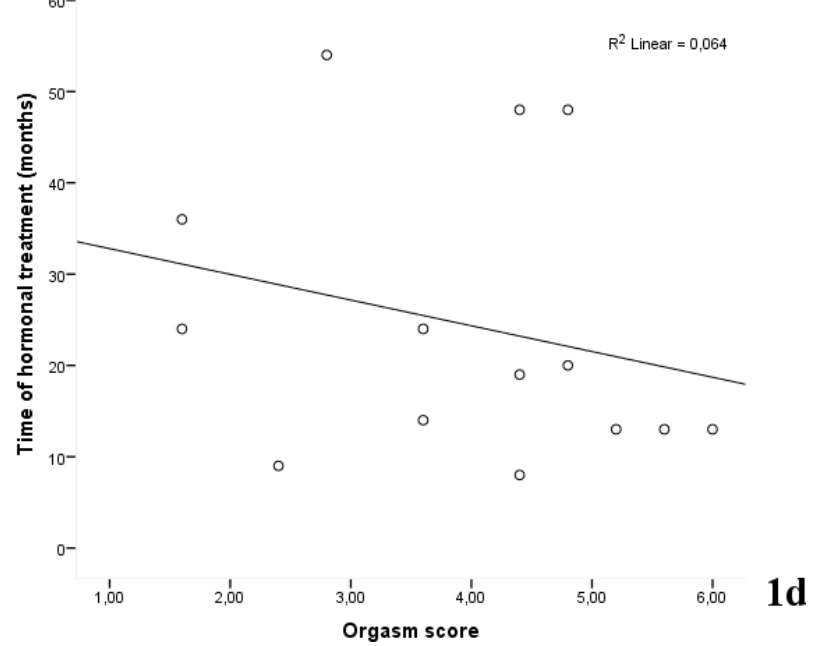

Figure 1: Correlation between the variable hormonal treatment time and a) endurance of all women $(n=26) ; b)$ endurance of sexually active women ( $n=14$ ); c) satisfaction score of the FSFI questionnaire ( $n=14)$; and d) FSFI questionnaire orgasm score $(n=14)$. 
The results clearly demonstrate the high rate of sexual dysfunction reported among post-breast cancer women. These findings corroborate previous studies, which found that about $70 \%$ of women affected by breast cancer experience at least one sexual dysfunction. ${ }^{(7,21)}$ Individually analyzing the domains which comprise the FSFI, it was found that the largest contributors to low scores in generating sexual dysfunction were the desire, lubrication, and pain during intercourse scores. It is known that vaginal dryness may cause pain during the intercourse. Thus, a multi-center study found that the decrease in sexual lubrication and consequent pain during intercourse were the most important risk factors associated with sexual dysfunction in women in the general population ${ }^{(22)}$. Generally, hormone therapy and early menopause are associated with symptoms of vaginal dryness, dyspareunia and arousal and orgasm disorder, (23) which may make the sexual dysfunction a more frequent problem in women affected by breast cancer and which carry out hormonal treatment.

Mourits et al. compared women who underwent high dosing with the standard chemotherapy dosage and found problems such as vaginal dryness and loss of sexual interest and satisfaction, especially in the group which received high chemotherapy dosage. ${ }^{(24)}$ In the present study, women who underwent hormone therapy for a longer period shown to be more likely to experience difficulty in reaching orgasm, and sexual satisfaction (Figure $1 \mathrm{c}$ and $1 \mathrm{~d}$, respectively). Perhaps, the prolonged time of hormone therapy is a trigger or aggravating of sexual problems. These findings suggest the early performance of physiotherapy in sexual matters in order to minimize the effects of hormonal treatment and improve the quality of life of these women.

Some studies has shown that the increase of the PFM strength by training leads to a significant improvement of sexual and social problems, as well as an improvement of sexual desire, orgasm and performance during sexual intercourse. ${ }^{(25,26)}$ Thus, the training of PFM increases the pelvic vascularization ${ }^{(27)}$ and enhances the clitoral sensitivity, ${ }^{(28)}$ and therefore has been suggested as a technique to promote the increase in desire, with higher possibility to improve the excitement and contribute to orgasm in the general population. ${ }^{(14)}$ Since the present study found both a negative association in the endurance of the PFM with the hormone treatment time, mainly in sexually active women (figure $1 \mathrm{a}$ and $1 \mathrm{~b}$ ), as a positive endurance correlation with orgasm domain, it is suggested that women undergoing hormone treatment are advised to initiate PFM training before or immediately after breast cancer surgery to minimize the effects of sexual dysfunction as well as to prevent PFM weakening.

Previous studies in the general population have verified that the muscle activity in individuals with PFM decreases with aging. ${ }^{(29)}$ Our results corroborate these findings, suggesting that the same applies to the post-breast cancer women. To improve the strength of PFM and restore pelvic dysfunctions which may be further aggravated by hormone therapy, PFM training should be proposed as a conservative treatment.

As a limitation of this study, there is the possibility of a type II error due mainly to the size of the sample, which could be larger. Another limitation would be self-assessment of the sexual function of women, since during the treatment adjustment period, the focus is on survival and problems regarding sexual function or body image may develop later. The strengths of this study are related to the used instruments. Despite the FSFI be a questionnaire and evaluate the symptoms subjectively, it is validated and considered a robust means of assessing sexual dysfunction, ${ }^{(18)}$ as well as the PERFECT scale that, although subjective, has been shown to be reliable and reproducible. ${ }^{(19)}$

\section{CONCLUSION}

In view of the results, it was possible to conclude that there is a high rate of sexual dysfunction among women post-breast cancer, and that the time of hormonal treatment has been associated with the symptoms of sexual dysfunction, regarding satisfaction and orgasm, and the worsening of maintaining the contraction of PFM (endurance).

\section{AUTHOR'S CONTRIBUTIONS}

TMAC: conception and design of the study, data acquisition, analysis and interpretation of data and writing of the manuscript.

TR: conception and design of the study, analysis and interpretation of data, statistical analysis and writing of the manuscript.

KMS: analysis and interpretation of data and writing of the manuscript.

SCTL: conception and design of the study, critical review of the manuscript regarding the important intellectual content.

CML: conception and design of the study, critical review of the manuscript regarding the important intellectual content.

Approval on the Research Ethics Committee n 597.606-0.

\section{CONFLICTS OF INTEREST}

Nothing to declare.

\section{AUTHOR DETAILS}

${ }^{1}$ Master's Degree student in Physiotherapy from the University of Santa Catarina UDESC, Florianópolis, Brazil: thaisalbanaz@hotmail.com.

${ }^{3}$ Master's Degree student in Physiotherapy from the University of Santa Catarina UDESC, Florianópolis, Brazil Email: keylasantosfisio@gmail.com.

${ }^{4} \mathrm{PhD}$ in High Performance Sports, Professor of the Graduate Program in Physical Therapy- University of the State of Santa Catarina- UDESC, Florianopolis, Brazil. Email: soraia.luz@udesc.br.

${ }^{5} \mathrm{PhD}$ in Medical Sociales Sciences, Professor of the Graduate Program in Physical Therapy- University of the State of Santa Catarina- UDESC, Florianopolis, Brazil. Email: clarissa.medeiros@udesc.br

\section{REFERENCES}

1. Câncer INd. Estimativa 2014. Incidência de Câncer no Brasil. Rio de Janeiro: Minitério da Saúde; 2014.

2. Lee $B L$, Liedke PE, Barrios $C H$, Simon SD, Finkelstein DM, Goss PE. Breast cancer in Brazil: present status and future goals. Lancet Oncol. 2012;13(3):95-102.

3. Rosa LMd, Radünz V. Taxa de sobrevida na mulher com câncer de mama: estudo de revisão. Texto Contexto Enferm. 2012;21:980-9. 
4. Gilbert E, Ussher JM, Perz J. Sexuality after breast cancer: a review. Maturitas. 2010;66(4):397-407.

5. Garrusi B, Faezee H. How do Iranian Women with Breast Cancer Conceptualize Sex and Body Image? Sex Disabil. 2008;26(3):159-65.

6. Archibald S, S. L, Byers SE, Tamlyn K, Worth J. Chemically-Induced Menopause and the Sexual Functioning of Breast Cancer Survivors. Women Ther. 2006;29(1-2):83-106.

7. Panjari M, Bell RJ, Davis SR. Sexual function after breast cancer. J Sex Med. 2011;8(1):294-302.

8. Macéa JR, Maceá MIM. Anatomia e fisiologia da resposta sexual feminina. In: Etienne MDA, Waitman MC, editors. Disfunções sexuais femininas: a fisioterapia como recurso terepêutico. 1 ed. São Paulo: Livraria Médica Paulista; 2006. p. 25-54.

9. Ganz PA, Rowland JH, Desmond K, Meyerowitz BE, Wyatt GE. Life after breast cancer: understanding women's health-related quality of life and sexual functioning. J Clin Oncol. 1998;16(2):501-14.

10. Schover LR, Yetman RJ, Tuason LJ, Meisler E, Esselstyn CB, Hermann RE, et al. Partial mastectomy and breast reconstruction. A comparison of their effects on psychosocial adjustment, body image, and sexuality. Cancer. 1995;75(1):54-64.

11. Alicikus ZA, Gorken IB, Sen RC, Kentli S, Kinay M, Alanyali H, et al. Psychosexual and body image aspects of quality of life in Turkish breast cancer patients: a comparison of breast conserving treatment and mastectomy. Tumori. 2009;95(2):212-8.

12. Avis NE, Crawford S, Manuel J. Psychosocial problems among younger women with breast cancer. Psychooncology. 2004;13(5):295-308.

13. Speer JJ, Hillenberg B, Sugrue DP, Blacker C, Kresge CL, Decker VB, et al. Study of sexual functioning determinants in breast cancer survivors. Breast J. 2005;11(6):440-7.

14. Graber B, Kline-Graber G. Female orgasm: role of pubococcygeus muscle. J Clin Psychiatry. 1979;40(8):348-51.

15. Shafik A. The role of the levator ani muscle in evacuation, sexual performance and pelvic floor disorders. Int Urogynecol J Pelvic Floor Dysfunct. 2000;11(6):361-76.

16. Kanter G, Rogers RG, Pauls RN, Kammerer-Doak D, Thakar R. A strong pelvic floor is associated with higher rates of sexual activity in women with pelvic floor disorders. Int Urogynecol J. 2015;26(7):991-6.

17. Haylen BT, de Ridder D, Freeman RM, Swift SE, Berghmans B, Lee J, et al. An International Urogynecological Association (IUGA)/International
Continence Society (ICS) joint report on the terminology for female pelvic floor dysfunction. Neurourol Urodyn. 2010;29(1):4-20.

18. Thiel RdRC, Dambros M, Palma PCR, Thiel M, Riccetto CLZ, Ramos MdF. Tradução para português, adaptação cultural e validação do Female Sexual Function Index. Rev Bras Ginecol Obstet. 2008;30:504-10.

19. Laycock J, Jerwood D. Pelvic floor muscle assessment: the perfect scheme. Physiotherapy. 2001;87(12):631-42.

20. Ortiz OC, Nuñez FC, Ibañez G. Evaluación funcional del piso pelviano femenino: classificación funcional. Bol Soc Latinoam Uroginecol Cir Vaginal. 1994;1(2):7-9.

21. Alder J, Zanetti R, Wight E, Urech C, Fink N, Bitzer J. Sexual dysfunction after premenopausal stage I and II breast cancer: do androgens play a role? J Sex Med. 2008;5(8):1898-906.

22. Blumel JE, Chedraui P, Baron G, Belzares E, Bencosme A, Calle A, et al. A large multinational study of vasomotor symptom prevalence, duration, and impact on quality of life in middle-aged women. Menopause. 2011;18(7):778-85.

23. Kedde H, van de Wiel HB, Weijmar Schultz WC, Wijsen C. Sexual dysfunction in young women with breast cancer. Support Care Cancer. 2013;21(1):271-80.

24. Mourits MJ, Bockermann I, de Vries EG, van der Zee AG, ten Hoor KA, van der Graaf WT, et al. Tamoxifen effects on subjective and psychosexual well-being, in a randomised breast cancer study comparing high-dose and standard-dose chemotherapy. Br J Cancer. 2002;86(10):1546-50.

25. Tamanini JTN, D’Ancona CAL, Botega NJ, Rodrigues Netto Jr N. Validação do "King's Health Questionnaire" para o português em mulheres com incontinência urinária. Rev Saude Publica. 2003;37:203-11.

26. Beji NK, Yalcin O, Erkan HA. The effect of pelvic floor training on sexual function of treated patients. Int Urogynecol J Pelvic Floor Dysfunct. 2003;14(4):234-8; discussion 8.

27. Ma Y, Qin H. Pelvic floor muscle exercises may improve female sexual function. Med Hypotheses. 2009;72(2):223.

28. Chambless DL, Sultan FE, Stern TE, O'Neill C, Garrison S, Jackson A. Effect of pubococcygeal exercise on coital orgasm in women. J Consult Clin Psychol. 1984;52(1):114-8.

29. Aukee P, Penttinen J, Airaksinen O. The effect of aging on the electromyographic activity of pelvic floor muscles. A comparative study among stress incontinent patients and asymptomatic women. Maturitas. 2003;44(4):253-7. 